\title{
The effects of conditioned taste aversions on schedule-induced polydipsia: An analysis of the initiation and postpellet temporal distribution of licking
}

\author{
ANTHONY L. RILEY, CORA LEE WETHERINGTON, ASHLEY M. WACHSMAN, \\ HARRIS A. FISHMAN, and MARY A. KAUTZ \\ The American University, Washington, D.C. \\ and National Institute on Drug Abuse, Rockville, Maryland
}

\begin{abstract}
Animals poisoned following the schedule-induced consumption of saccharin initially continued to drink following spaced pellet deliveries. Neither the initiation of postpellet drinking (i.e., bout initiation) nor the size and duration of the bouts was effected by the conditioned aversion procedure. With repeated conditioning trials (i.e., repeated pairings of saccharin and $\mathrm{LiCl}$ ), scheduleinduced drinking was eventually reduced. The specific components underlying schedule-induced consumption, however, were differentially affected by the aversion training. Specifically, the decrease in schedule-induced drinking was effected primarily by a decrease in licking occurring between 10 and $60 \mathrm{sec}$ after pellet delivery. Bout initiation and licking immediately postpellet (i.e., within the first $10 \mathrm{sec}$ following pellet delivery) were most resistant to suppression and appeared to be responsible for the relative insensitivity of schedule-induced drinking to conditioned taste aversions. The differential effects of taste aversion conditioning on individual components of elicited behavior are discussed.
\end{abstract}

If water is made available to a food-deprived rat receiving food pellets on an interval schedule, the rat consumes voluminous amounts of water during the experimental session (Falk, 1961, 1969, 1971). Because consumption appears to be generated by the scheduled food deliveries, this behavior has been termed schedule-induced polydipsia (SIP; see Falk, 1961).

Since the original demonstration of SIP, a wide range of manipulations have been examined for their effects on its development and maintenance (for reviews, see Christian, Schaeffer, \& King, 1977; Falk, 1971; Roper, 1978; Staddon, 1977; Wetherington, 1982). One manipulation has involved the interaction of SIP and conditioned taste aversions (CTAs) (Riley, Lotter, \& Kulkosky, 1979; see also Bond \& Corfield-Sumner, 1978; Brett \& Levine, 1981; Clarke \& Westbrook, 1978; Corfield-Sumner \& Bond, 1978; Roll, Schaeffer, \& Smith, 1969). In Riley et al.'s (1979) study, rats initially had access to water while receiving spaced food pellets on a fixed-time 60 sec schedule. After SIP had developed, water was replaced by a saccharin solution during the experimental session. Immediately following this session, the animals were given an injection of either the emetic $\mathrm{LiCl}$ or the distilled-

This research was supported in part by funds from grants from the Mellon Foundation and the National Science Foundation (BNS-8406445). Request for reprints should be sent to either Anthony L. Riley, Psychopharmacology Laboratory, Department of Psychology. The American University, Washington, DC 20016, or Cora Lee Wetherington, National Institute on Drug Abuse, 5600 Fishers Lane, Parklawn Building, Room 10A-16, Rockville, MD 20857. water vehicle. Typically, when consumption of a flavored solution such as saccharin is paired with $\mathrm{LiCl}$-induced toxicosis, a robust taste aversion is acquired and the animal avoids the subsequent ingestion of the poisonassociated taste (Garcia \& Ervin, 1968; Revusky \& Garcia, 1970; Riley \& Tuck, 1985; Rozin \& Kalat, 1971). Thus, it was surprising that schedule-induced saccharin consumption during subsequent experimental sessions was only marginally and temporarily affected (Riley et al., 1979, Experiment 2). A subsequent study by Riley, Hyson, Baker, and Kulkosky (1980) demonstrated that after repeated pairings of saccharin and poison, scheduleinduced saccharin consumption was eventually reduced; however, even under these conditions saccharin consumption was affected considerably less than it is under water deprivation or under conditions in which the same number of food pellets is presented en masse at the start of the session, that is, massed feeding. Furthermore, recovery of saccharin drinking during extinction (that is, when saccharin consumption is no longer paired with $\mathrm{LiCl}$ ) is much faster under SIP than under the water-deprivation or massed-feeding conditions (Hyson, Sickel, Kulkosky, \& Riley, 1981; Riley et al., 1980; for a review, see Riley \& Wetherington, 1988).

Consideration of the effects of taste aversions on other behaviors may provide some insight into the relative insensitivity of SIP to taste aversion conditioning. In an analysis of the effects of taste aversions on predation in the grasshopper mouse, Langley (1981) reported that when mice were given an injection of $\mathrm{LiCl}$ immediately follow- 
ing attack on or consumption of a live cricket, consumption of the prey was rapidly suppressed, although the mice continued to attack and kill the prey. Even after five conditioning trials (the point at which consumption of the prey was totally suppressed), over $75 \%$ of the mice still attacked the prey, with little change in attack latency (as compared with nonpoisoned control mice). Effects of conditioned aversions on predation have been reported by others, who also have noted that although conditioned aversion training can eventually suppress all aspects of predation, different components of predation appear differentially sensitive to the effects of conditioning (Berg \& Baenninger, 1974; Clody \& Vogel, 1973; Gay, Leaf, \& Arble, 1975; Gustavson, Garcia, Hankins, \& Rusiniak, 1974). As noted by Gay et al. (1975), “typically, drugs which produce learned aversions to mouse-killing seem to affect eating of the prey first, killing second and attack last" (p. 44). This generalization that early components of predatory behavior are least sensitive to conditioned aversions and that latter components are most sensitive also applies to copulatory behavior. Johnston and his colleagues (Johnston, Zahorik, Immler, \& Zakon, 1978; see also Johnston \& Zahorik, 1975; Zahorik \& Johnston, 1976), for example, reported that male rats injected with $\mathrm{LiCl}$ following exposure to vaginal secretions subsequently decreased the overall number of mounts, increased the latency to mount, and decreased the overall time spent mounting an estrous female. The time spent in precopulatory sniffing and licking of the vagina of the estrous female, however, was unaffected (see also Emmerick \& Snowdon, 1976). In other words, it was the initial components of copulatory behavior, that is, licking and sniffing, that were most resistant to aversion learning, and the terminal components, that is, mounting and ejaculation, that were least resistant. It is interesting in this context that Reidinger and Mason (1986), in a study demonstrating the weak effects of taste aversion conditioning on autogrooming in the rat, reported that aversion conditioning affected only grooming duration and left the initiation of grooming episodes unaffected.

SIP also can be conceptualized as having initial and terminal components (see Keehn \& Stoyanov, 1986; King \& Schaeffer, 1973). The initial component is the initiation of a postfood drinking episode, measured as the probability of licking following pellet delivery (i.e., bout initiation). The terminal component of SIP corresponds to the latter portions of the postpellet licking bout (i.e., bout size and duration). On the basis of the differential effects of taste aversions on the initial and terminal components of sex and predation, it might be expected that the initial component of SIP (i.e., bout initiation) would be resistant to the effects of aversion training, whereas the latter components (i.e., bout size and duration) would be suppressed. Thus, although taste aversions might suppress some components of SIP, others would be relatively unaffected. Such differential effects of taste aversions on components of SIP might be responsible in part for the relative insensitivity of SIP to taste aversion conditioning. These predictions were tested in the present study.

\section{METHOD}

\section{Subjects}

The subjects were 8 experimentally naive female rats of LongEvans descent, approximately 120 days of age at the beginning of the experiment. They were individually housed in wire-mesh cages and maintained on a 12:12-h light:dark cycle (lights on at $0800 \mathrm{~h}$ ) and at an ambient temperature of $23^{\circ} \mathrm{C}$. All subjects were maintained at $85 \%$ of their free-feeding weights by food restriction. Water was continuously available.

\section{Apparatus}

Four identical chambers $(26.5 \times 19.2 \times 16.0 \mathrm{~cm})$ were used. The sides and the ceiling of each chamber were made of $0.6-\mathrm{cm}$ clear Plexiglas, and the grid floor was constructed of $0.4-\mathrm{cm}$-diam stainless steel rods spaced $2 \mathrm{~cm}$ apart. A $1 \times 3 \mathrm{~cm}$ food hopper was centered on the front wall $3 \mathrm{~cm}$ above the grid floor. A graduated Nalgene drinking tube located outside the chamber was flush with the outer wall $3 \mathrm{~cm}$ above the grid floor and $7 \mathrm{~cm}$ to the left of the food hopper. Licks were detected by a drinkometer (Lafayette Model 55008). A 28-V houselight, continuously illuminated throughout the session, was centered on the front wall of each chamber $13.5 \mathrm{~cm}$ above the grid floor.

Programming of events and recording of lick responses were accomplished by a TRS-80 Model III microcomputer interfaced to the chambers with an Alpha Interfacer 80. For a detailed description of the hardware and software used in the conduct of this research, see Riley, Schoening, and Wetherington (1985).

\section{Procedure}

Phase 1: Schedule-induced polydipsia. During each session, the subjects were presented with a single 45-mg Noyes pellet once every $60 \mathrm{sec}$ on a fixed-time (FT) 60 -sec schedule until a total of 60 pellets had been delivered. Water was continuously available via graduated Nalgene tubes. After each session, water intake for each rat was recorded and lick data were stored to disk. If necessary, the animals were supplementally fed Purina Rat Chow in the home cages to maintain their body weights at $85 \%$ of their freefeeding weights. This phase lasted for 14 consecutive days.

Phase 2: Taste aversion conditioning. In the first session of this phase (Session 15), all subjects received the FT food deliveries as during Phase 1; however, a novel saccharin solution $(0.1 \% \mathrm{w} / \mathrm{v}$ sodium saccharin, Fisher Purified) was substituted for water. Immediately after the session, the subjects were divided into two groups matched on saccharin consumption ( $n=4$ per group) and were given an intraperitoneal (i.p.) injection of either $1.8 \mathrm{mEq} 0.15 \mathrm{M}$ $\mathrm{LiCl}$ (Group L) or distilled water (Group W). Following the injections, subjects were returned to their home cages. In the next two sessions, water was available as in Phase 1 . A conditioning session (saccharin access followed by $\mathrm{LiCl}$ ) and two subsequent recovery sessions (water access) alternated until all subjects had received four complete cycles of conditioning and recovery. On the day following the final recovery session, all subjects were given access to saccharin during the free-food deliveries. No injections followed this final session.

\section{RESULTS}

Figure 1 illustrates the overall amount of saccharin consumed and the probability of initiating a bout (i.e., making at least a single lick following a pellet delivery) for 

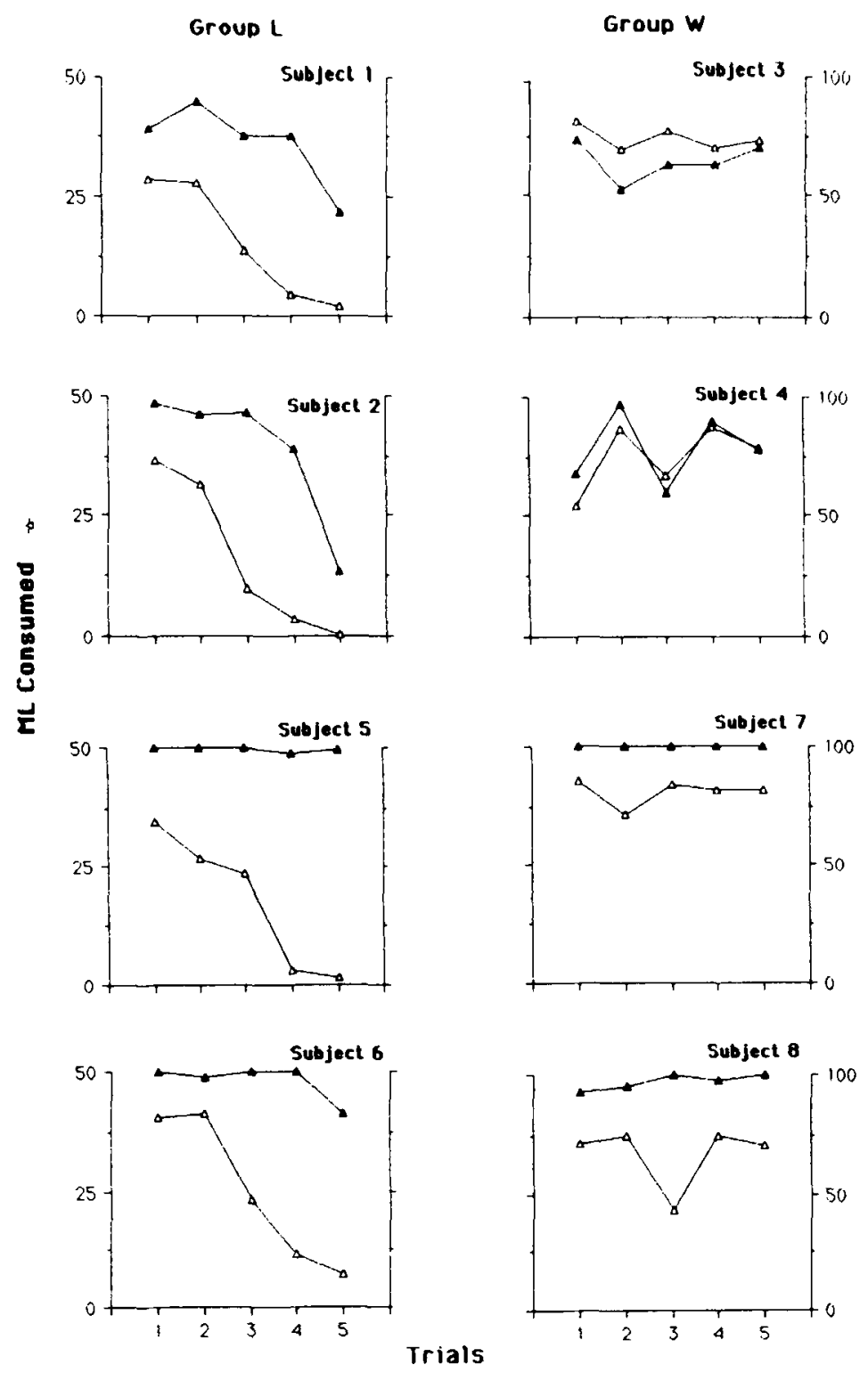

Figure 1. Saccharin consumption and hout probability for each subject in Group L (left panel) and Group W (right panel) over repeated exposures to saccharin.

individual subjects in Groups $\mathrm{L}$ and $\mathrm{W}$ over the five saccharin exposures in Phase 2. Subjects injected with $\mathrm{LiCl}$ following saccharin consumption during the spaced food deliveries (i.e., Group L; left-hand column) displayed a reduction in saccharin consumption over exposures. On the initial conditioning trial, all subjects in this group drank over $25 \mathrm{ml}$ (range, $28-41 \mathrm{ml}$ ); by the final saccharin exposure (i.e., after four conditioning trials), only a single subject drank greater than $2 \mathrm{ml}$ (range, 0-6 ml). Subjects injected with the distilled-water vehicle throughout this phase (i.e., Group W; right-hand column) showed no systematic change in saccharin consumption over repeated saccharin exposures, drinking approximately $35 \mathrm{ml}$ (range, $28-41 \mathrm{ml}$ ) on the final exposure to saccharin.
Although subjects in Group $\mathrm{L}$ decreased their saccharin consumption after two conditioning trials (Figure 1, Trial 3), bout probability was not affected until the final saccharin exposure (i.e., after four trials), and even here, the effect was substantial for only 2 subjects (Subjects 1 and 2). Although bout probability was reduced on the final saccharin exposure for these 2 subjects, it was not totally suppressed. On this day, when Subjects 1 and 2 consumed less than $2 \mathrm{ml}$ each, they still initiated drinking bouts following 43\% (Subject 1) and 27\% (Subject 2) of the delivered pellets. The other 2 subjects in Group L, Subjects 5 and 6 , continued to initiate drinking bouts after $85 \%$ and $100 \%$, respectively, of the delivered pellets on the final saccharin exposure, although their consumption was reduced to less than $1 \mathrm{ml}$ (Subject 5) and $6 \mathrm{ml}$ 
(Subject 6). Bout probability did not consistently change over saccharin exposures for any subject in Group W.

Figure 2 illustrates the number of licks per bout over repeated saccharin exposures for individual subjects in Groups $\mathrm{L}$ and $\mathrm{W}$. This measure was computed by dividing total saccharin licks by the total number of bouts (i.e., number of intervals containing at least one lick). All subjects in Group L (upper panel) displayed a decrease in the number of licks per bout over conditioning trials. On the first conditioning trial, these subjects displayed an average of 122.9 licks per bout (range, 90.0-209.5). On the final saccharin exposure, the number of licks per bout was reduced to an average of 18.5 (range, 11.4-27.1). Subjects in Group W (lower panel) did not systematically change in number of licks per bout over conditioning trials (range on the first and final saccharin exposures, 119.4-161.2 and 83.7-164.4, respectively).

Figure 3 illustrates the postpellet temporal distribution of licks averaged across 60 pellets for each saccharin exposure for the individual subjects in Group L. The data were averaged across all saccharin exposures for subjects in Group W because there were no systematic changes in the postpellet temporal distribution of licking across the repeated saccharin exposures for this group. All subjects in Group W (right panel) displayed a postpellet licking pattern typical of SIP, that is, an initial low rate of licking immediately postpellet followed by an increase and then a decrease in lick rate with time since pellet delivery. This pattern was also evident for all subjects in Group $L$ on the initial exposure to saccharin.

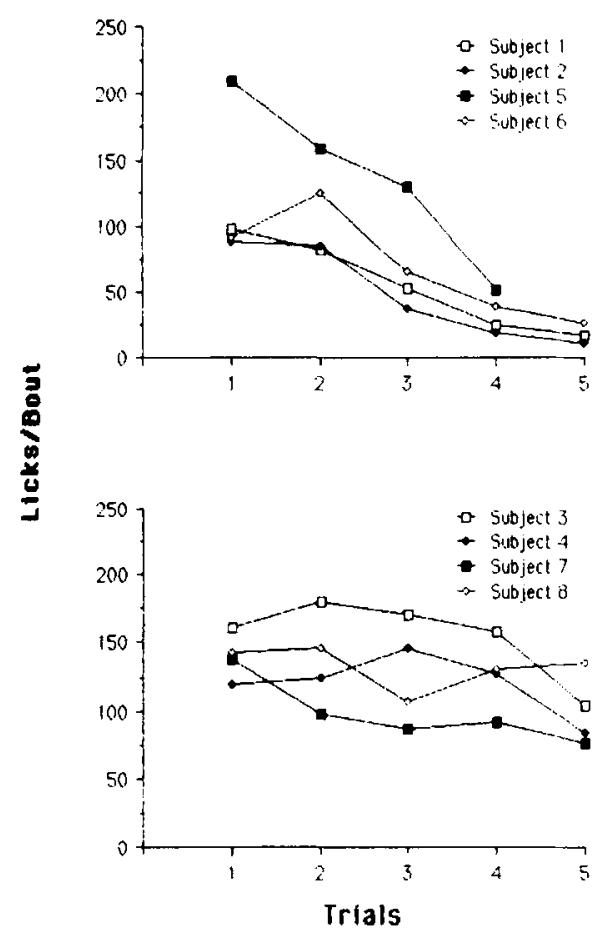

Figure 2. Licks per bout for each subject in Group L (top panel) and Group W (bottom panel) over repeated exposures to saccharin. For Subject 5 in Group $L$, data for the final exposure to saccharin were lost due to equipment malfunction.
By the third exposure to saccharin (after two conditioning trials), the postpellet pattern of licking was clearly abbreviated in all subjects in Group $L\left(\chi_{r}^{2}=14.6\right.$, $p<.05$ ). For example, although lick rates for Subjects 1 , 2 , and 6 on this conditioning trial were unaffected in the first 5 -sec interval and reduced by no more than $32 \%$ in the second 5-sec interval, they were suppressed by a range of $41 \%-84 \%$ and $72 \%-96 \%$ in the third and fourth intervals, respectively. Lick rates also appeared suppressed for these subjects beyond the fourth 5-sec interval, although because of the low base rate of licking at these periods the suppression was less clear. The changes in licking patterns for Subject 5 were somewhat different in that this subject initially had a higher rate of licking in the latter part of the interpellet interval than did Subjects 1, 2 , and 6 . On the third exposure to saccharin, although licking was unaffected in the first six 5-sec intervals it was suppressed over the remainder of the interpellet interval (see also Day 2).

With repeated conditioning trials, overall licking was reduced. When licking did occur, it was generally restricted to the first part of the interpellet interval (see Subject 1, Day 4; Subject 2, Days 4 and 5; Subject 5, Day 4; Subject 6, Days 4 and 5). Lick rate data were not available for Subject 5 on the final saccharin exposure.

\section{DISCUSSION}

A single conditioning trial resulted in little change in saccharin consumption, the probability of initiating postpellet licking, the size of the bout, or the temporal distribution of licking. All of these measures were eventually affected with repeated conditioning trials; however, the rates at which these measures were affected were different. Changes in bout probability did not parallel decreases in consumption; that is, the rats continued to initiate licking following pellet delivery even when consumption was markedly suppressed. In fact, bout initiation was not clearly affected until consumption was less than $10 \%$ of the preconditioning levels. The decrease in polydipsic consumption was effected primarily by a reduction in the number of licks within a bout of postpellet drinking. The average bout size was reduced from approximately 120 to 20 licks as consumption decreased from an average of 35 to $3 \mathrm{ml}$. This reduction in bout size was reflected in changes in the postpellet temporal distribution of licking. Specifically, as consumption initially decreased there was a graded decrement in the number of licks in the middle and latter portions of the postpellet interval, whereas the number of licks immediately postpellet, that is, within the first $5 \mathrm{sec}$ following pellet delivery, was unaffected. Reductions in the lick rate immediately following pellet delivery did not occur until consumption was reduced to less than $20 \%$ of the preconditioning levels.

The fact that taste aversions shorten bout size and duration while only marginally affecting bout initiation and immediate postpellet licking is consistent with the differential effects of taste aversion conditioning on the individual components of sexual behavior (Emmerick \& Snowdon, 

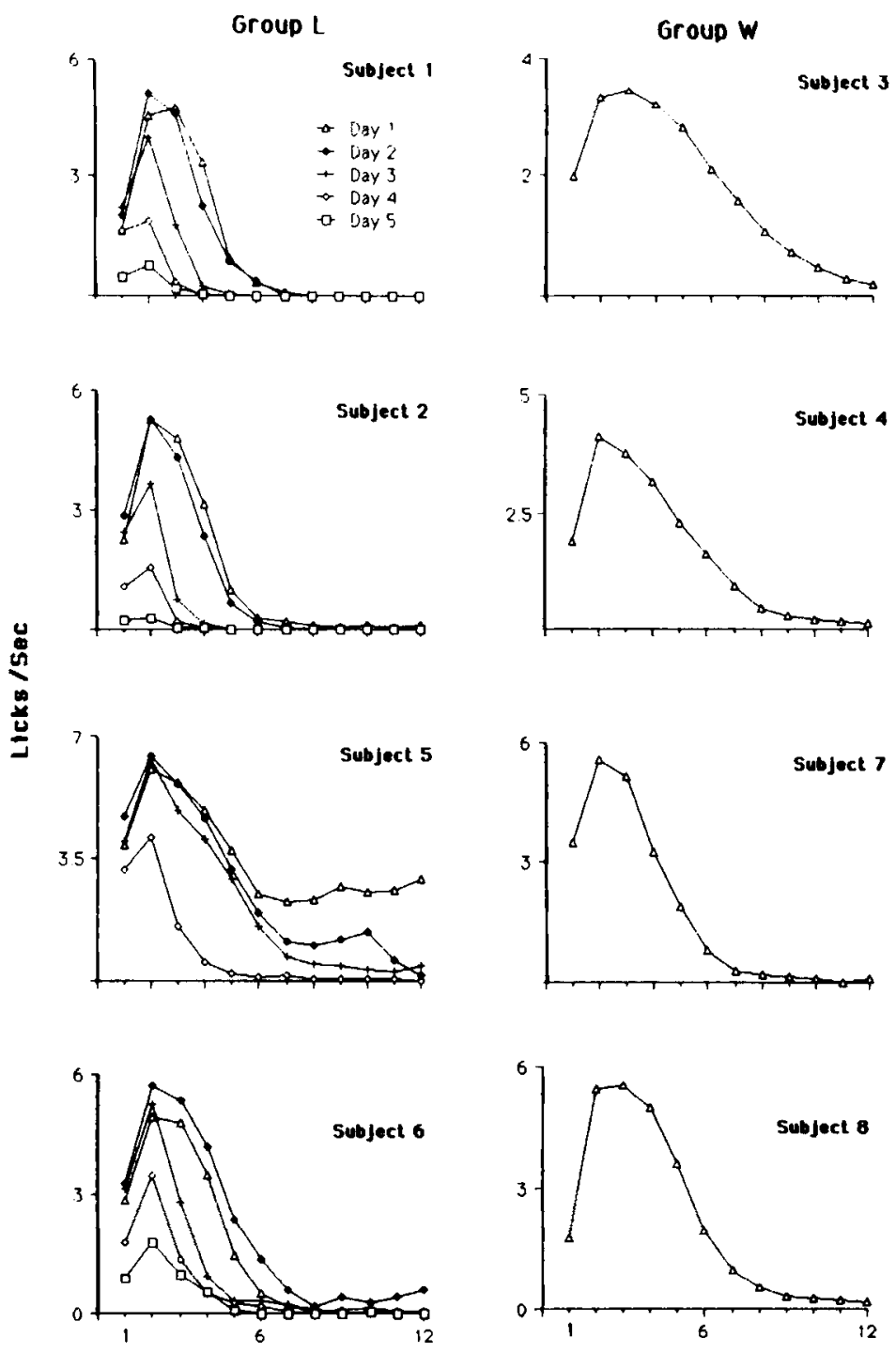

5-Sec intervals

Figure 3. Mean licks per second across consecutive 5-sec bins within the interpellet interval for each subject in Group $L$ (left panel) over repeated exposures to saccharin. For Group W (right panel), data are collapsed over sessions (see text). Data for Subject 5 on the final saccharin exposure were lost due to equipment malfunction.

1976; Johnston et al., 1978), predation (Berg \& Baenninger, 1974; Clody \& Vogel, 1973; Gay et al., 1975; Langley, 1981) and autogrooming (Reidinger \& Mason, 1986). As noted earlier, the initial sniffing and licking responses in sexual behavior, the initial attack and killing in predation, and the initiation of autogrooming either were unaffected or were reduced only with repeated conditioning trials, an effect quite different from the rapid suppression of the terminal components of the behaviors (i.e., ejaculation, consumption, and grooming duration, respectively).

Several explanations exist for the differential effects of aversion conditioning on the individual responses in behavioral sequences. It has been suggested that such effects are a consequence of differential conditioning; that is, the stimuli controlling the various behaviors are differentially associated with toxicosis (see Gustavson et al., 1974). The differential effects presumably reflect varying rates of acquisition of the aversion. It is also possible that the stimuli that control the initial and terminal components are, in fact, equally associated with toxicosis, but that the elicitation by the initial component stimuli (or others) simply overrides the conditioned avoidance (see Langley, 1979). The fact that mice's attacks on crickets can be rapidly suppressed by aversion conditioning if the stimuli triggering attack are removed (e.g., by presenting a dead cricket) supports such a suggestion (Langley, 1981).

Riley et al. (1979; see also Riley \& Wetherington, 1988) reported that SIP is relatively insensitive to aver- 
sion conditioning; their report was based primarily on the fact that repeated conditioning trials are needed to suppress SIP and that SIP rapidly extinguishes once conditioning is terminated. The present data may suggest a basis for this relative insensitivity. Specifically, although aversion conditioning can readily reduce the size and duration of postpellet drinking bouts, the initiation of such bouts and the initial licks in the postpellet bout are more resistant to aversion conditioning and require repeated conditioning trials to suppress. The insensitivity of bout initiation and immediate postpellet licking to aversion conditioning may underlie the relative inability of taste aversions to suppress the schedule-induced consumption of poison-associated tastes. It remains unknown why the initial sequence of SIP is resistant to suppression by taste aversion conditioning. The fact that tastes paired with $\mathrm{LiCl}$ under schedules of spaced feeding readily suppress consumption when the subjects are given access to the poisonassociated solution under water deprivation (Hyson et al., 1981; see also Riley, Peele, Richard, \& Kulkosky, 1981) indicates that aversions are, in fact, acquired to the taste. This suggests that the eliciting properties of spaced feedings, that is, the strong tendency to initiate bouts of drinking, simply override the display of the aversion. Although the relative insensitivity of bout initiation and immediate postpellet licking to aversion conditioning may account for the relatively weak effect aversion conditioning has on schedule-induced polysipsia, it remains to be determined whether the initial components of drinking behavior more readily affected by taste aversion learning are more easily suppressed. Indices of taste aversion learning are generally restricted to gross measures of absolute consumption and, as such, do not allow an assessment of changes in patterns of consumption (bout initiation, size, or duration) with conditioning (see Riley \& Tuck, 1985).

\section{REFERENCES}

Berg, D., \&aenninger, R. (1974). Predation: Separation of aggressive and hunger motivation by conditioned aversion. Journal of Comparative \& Physiological Psychology, 86, 601-606.

Bond, N., Corfigld-Sumner, P. K. (1978). Taste aversion learning and schedule-induced polydipsia. Animal Leaming \& Behavior, 6. 413-416.

Brett, L. P., Levine, S. (1981). The pituitary-adrenal response to "minimized" schedule-induced drinking. Physiology \& Behavior, 26, 153-158.

Christian, W., Schaefrer, R., \& KING, G. (1977). Schedule-induced behavior: Research and theory. Montreal: Eden Press.

Clarke, J. C., \& Westbrook, R. F. (1978). Control of polydipsic drinking by a taste aversion procedure. Pharmacology, Biochemistry \& Behavior, 9, 283-286.

CLODY, D. E., \& VoGeL, J. R. (1973). Drug-induced conditioned aversion to mouse-killing in rats. Pharmacology, Biochemistry \& Behavior, $1,477-481$.

Corfield-Sumner, P. K., Bond, N. W. (1978). Taste aversion learning and schedule-induced alcohol consumption in rats. Pharmacology, Biochemistry \& Behavior, 9, 731-733.

Emmerick, J. J., SNowdon, C. T. (1976). Fajlure to show modification of male hamster mating behavior through taste/odor aversion learning. Joumal of Comparative \& Physiological Psychology, 90 , 857-869.

FALK, J. L. (1961). Production of polydipsia in rats by an intermittent food schedule. Science, 133, 195-196.

FALK, J. L. (1969). Conditions producing psychogenic polydipsia in animals. Annals of the New York Academy of Sciences, 157, 569-593.

FALK, J. L. (1971). The nature and determinants of adjunctive behavior. Physiology \& Behavior, 6, 577-588.

GARCIA, J., ERvin, F. R. (1968). Gustatory-visceral and telereceptorcutaneous conditioning: Adaptations in internal and external milieus. Communications in Behavioral Biology, 1, 389-415.

Gay, P. E., Leaf, R. C., \& ARBLe, F. B. (1975). Inhibitory effects of pre- and posttest drugs on mouse killing by rats. Pharmacology, Biochemistry \& Behavior, 3, 33-45.

Gustavson, C. R., Garcia, J., Hankins, W. G., Rusiniak, K. W. (1974). Coyote predation control by aversive conditioning. Science, 184, 581-583.

Hyson, R. L., Sickel, J. L., Kulkosky, P. J., Riley, A. L. (1981). The insensitivity of schedule-induced polydipsia to conditioned taste aversions: Effects of amount consumed during conditioning. Animal Learning \& Behavior, 9, 281-286.

Johnston, R. E., ZAhorik, D. M. (1975). Taste aversions to sexual attractants. Science, 189, 893-894.

Johnston, R. E., ZAhORIK, D. M., IMmLER, K., ZAKON, H. (1978). Alterations of male sexual behavior by learned aversions to hamster vaginal secretion. Journal of Comparative \& Physiological Psychology, 92, 85-93.

Keenn, J. D., Stoyanov, E. (1986). The development of adjunctive drinking by rats: Conditioned and unconditioned components. Animal Learning \& Behavior, 14, 411-415.

KING, G. D., SChaefFer, R. W. (1973). Developmental analysis of schedule-induced polydipsia. Psychological Reports, 32, 1087-1095.

LANGLEY, W. (1981). Failure of food-aversion conditioning to suppress predatory attack of the grasshopper mouse, Onychomys leucogaster. Behavioral \& Neural Biology, 33, 317-333.

LAWRENCE, G. J., KIEFer, S. W. (1987). Cessation of male ral copulatory behavior using illness as punishment: Facilitation with a novel odor. Behavioral Neurosciences, 101, 289-291.

REIDINGER, R. F., JR., MASON, J. R. (1986). Effects of learned flavor avoidance on grooming in rats. Physiology \& Behavior, 37, 925-931.

Revusky, S., \& GARCIA, J. (1970). Learned associations over long delays. In G. Bower \& J. Spence (Eds.), Psychology of learning and motivation: Advances in research and theory (Vol. 4, pp. 1-84). New York: Academic Press

Riley, A. L., Hyson, R. L., BAker, C. S., \& Kulxosky, P. J. (1980). The interaction of conditioned taste aversions and schedule-induced polydipsia: Effects of repeated conditioning trials. Animal Learning \& Behavior, 8, 211-217.

Riley, A. L., Lotrer, E. C., Kulkosky, P. J. (1979). The effects of conditioned taste aversions on the acquisition and retention of schedule-induced polydipsia. Animal Learning \& Behavior, 7, 3-12.

Riley, A. L., Peele, D. B., Richard, K. D., Kulkosky, P. J. (1981). The interaction of conditioned taste aversions and scheduleinduced polydipsia: Availability of alternative behaviors. Animal Leaming \& Behavior, 9, 287-290.

Riley, A. L., Schozning, G., Wetherington, C. L. (1985). A software package for the microcomputer control and analysis of research on schedule-induced polydipsia. Physiology \& Behavior, 35, 825-829.

RILEY, A. L., \& TuCK, D. L. (1985). Conditioned food aversions: A bibliography. Annals of the New York Academy of Sciences, 443, $381-437$.

RILEY, A. L., Wetherington, C. L. (1988). Schedule-induced polydipsia: Is the rat a small furry human? (An analysis of an animal model of human alcoholism). In S. B. Klein \& R. R. Mowrer (Eds.), Contemporary leaming theories. Hillsdale, NJ: Erlbaum.

Roll, D., SChAefFer, R. W., \& SMITH, J. C. (1969). Effects of a con- 
ditioned taste aversion on schedule-induced polydipsia. Psychonomic Science, 16, 39-41.

ROPER, T. J. (1978). Diversity and substitutability of adjunctive activities under fixed-interval schedules of food reinforcement. Journal of the Experimental Analysis of Behavior, 30, 83-96.

Rozin, P., \&ALAT, J. W. (1971). Specific hungers and poison avoidance as adaptive specializations of learning. Psychological Review, 78, 459-486.

Staddon, J. E. R. (1977). Schedule-induced behavior. In W. K. Honig \& J. E. R. Staddon (Eds.), Handbook of operant behavior (pp. 125-152). Englewood Cliffs, NJ: Prentice-Hall.
WETHERINGTON, C. L. (1982). Is adjunctive behavior a third class of behavior? Neuroscience \& Biobehavioral Reviews, 6, 329-350.

ZAhorik, D. M., Johnston, R. E. (1976). Taste aversions to food flavors and vaginal secretions in golden hamsters. Jourmal of Comparative \& Physiological Psychology, 90, 57-66.

(Manuscript received August 28, 1987; revision accepted for publication March 1, 1988.) 